\title{
La política exterior en la folletería mexicana del siglo XIX
}

Laura Muñoz M. INSTITUTO MORA

\author{
Reseña los 964 folletos dedicados a la política exterior \\ localizados por el proyecto de folletería del Instituto \\ Mora, poniendo particular énfasis en los que tratan la \\ región del Caribe.
}

INTRODUCCIÓN

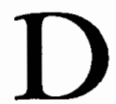

e autor anónimo o de reconocida fama entre sus contemporáneos y, aun después, de sello oficial ${ }^{1}$ o producto de la pluma de ciudadanos interesados en los procesos sociales y políticos de la época -quienes pagaban sus impresiones o fundaban sus imprentas,$-{ }^{2}$ los folletos

1 Publicadas por el Congreso, la Secretaría de Relaciones Interiores y Exteriores o la de Hacienda por ejemplo.

2 Entre ellos Mariano Michelena, Manuel Marchena y José Joaquín Fernández de Lizardi que publicó, entre 1822 y 1823 , cinco folletos constituyen una fuente importante de información, tanto por su contenido como por su número y variedad de títulos sobre ciertos temas que nos permiten conocer los intereses de un sector de la sociedad mexicana. Escritos para informar o para debatic cuestiones coyunturales, $y$ aunque de circulación variable, fueron un medio de expresión que propició la reflexión, la comunicación y la discusión.

en la imprenta de su propiedad, además de utilizar los servicios de otras como la de Ontiveros, la de Herculana del Villar, la imprenta a cargo de Juan Cabrera o la de la calle de Ortega. 
En la folletería se refleja la preocupación que causaron ciertos acontecimientos, las respuestas y alternativas. que propusieron las facciones políticas, la polémica alrededor de determinados temas, la inquietud por desarrollar argumentos en torno a asuntos de primordial importancia para el interés nacional y que, tal vez, no pudieron expresarse o no quisieron ser formulados en otros ámbitos, como la prensa o los círculos del poder, pero que también se dirigieron a él. Liberales, conservadores, republicanos, monarquistas, hispanófilos o hispanófobos, extranjeros y nacionales encontraron en el folleto un medio adecuado para emitir sus opiniones, ya fueran oficiales o particulares. Las motivaciones para escribirlos y publicarlos respondieron a necesidades individuales o de grupo y sirvieron para presentar planteamientos personales o para justificar acciones de ciertas autoridades o instituciones. La folletería resulta, entonces, testigo de una sociedad y de una época.

Las siguientes líneas son el resultado de una primera aproximación al estudio de una fuente documental de riqueza incalculable para conocer la historia de México. De la enorme cantidad de folletos - publicados en México o en el extranjero- reunidos en la base de datos Folletería Mexicana del Siglo XIX, provenientes de diversos acervos, seleccionamos aquellos que abordan los asuntos fundamentales de la política exterior decimonónica de México, o que tocan aspectos generales de política exterior. ${ }^{3}$ Del conjunto

${ }^{3}$ Las cifras proporcionadas en este trabajo corresponden a lo que está capturado en la ba- formado, llamó nuestra atención la presencia de ciertos materiales en los que se hacía referencia a la región caribeña, a los vínculos establecidos con ella, o a los intereses de México hacia esa frontera, y a ellos dedicaremos un comentario especial.

\section{CONSIDERACIONES GENERALES}

La base recoge un total de aproximadamente 26500 folletos para el periodo que se extiende de 1821 a 1910 , de los cuales, 964 pertenecen al rubro Política exterior, repartidos como se ve en la siguiente página.

A primera vista podemos inferirque, en las primeras décadas de vicla independiente, la necesidad de expresarse y debatir en torno a la difícil defensa de los intereses de México en el ámbito internacional era mayor. El peligro que representaba la ambición europea y estadunidense así lo determinaban: la amenaza española, la cuestión de Texas, el bloqueo francés, etcétera. Sin embargo, aunque la intimidación externa no desapareció del escenario nacional hasta que las armas mexicanas triunfaron ante la intervención francesa, la disminución en el número de folletos en torno a los asuntos vinculados a la relación de México con el exteriorfue notable conforme fue avanzando el siglo y, de manera especial, en el último periodo, seguramente debido a que ya no estaba en cuestión la importancia de promover la política exterior y a que la mayor parte de los

se de datos, no al número real de folletos que existen en los acervos. 
Total de folletos

Total sobre
Politica exterior

432

1821-1836

1837-1851

1852-1867

1868-1880

1881-1892

1893-1910
7167

4361

3786

2869

3327

4205
237

149

50

66

30
Relacionados con la región Golfo-Caribe $y$ Antillas

$\begin{array}{cc}41^{\mathrm{a}} & 4^{b} \\ 7 & \\ 5^{\mathrm{c}} & \\ 3 & \\ 4 & 1 \\ 5 & 2\end{array}$

"Incluye los folletos referentes al bloqueo y rendición de Ulúa (publicados en la ciudad de México, Puebla, Xalapa y San Luis Potosí); la invasión española (impresos en la ciudad de México, San Luis Potosí y La Habana), sobre Yucatán (uno, de la ciudad de México), Veracruz (dos, sobre acontecimientos diversos y publicados en Veracruz y Puebla), Sisal, Tampico y La Habana.

b Folletos en cuyo título aparece La Habana.

c Publicados por imprentas establecidas en distintos puntos del litoral.

temas en esa época no eran de carácter coyuntural. Es probable que el debate de éstos se haya trasladado a otros medios, como a la prensa, o que se quedara en la correspondencia oficial -ya sea regular o reservada-y que el espacio que ofrecía la folletería fuera ocupado por otras temáticas relativas a la política interna. ${ }^{4}$

En cuanto a los títulos que hacen referencia al Caribe, o a los vínculos con él, quedan -como veremos más adelante-inmersos claramente en el rubro concerniente a la defensa nacional.

¿Cuáles serían los temas recurrentes a lo largo del periodo abordado? En un esfuerzo de sintesis, señalaríamos la preservación de la independencia, soberanía e integridad territorial, expresados a través de problemas concretos como el de la reconquista espa-

${ }^{4}$ Véase el trabajo de Graziella Altamirano y María Eugenia Arias, "Los folletos, reflejos de una época, 1893-1910", en este mismo número. ñola, la intervención francesa, el imperio, la guerra con Estados Uniclos, la cuestión texana o las negociaciones limítrofes.

También se encuentran folletos acerca de cuestiones que tienen que ver con el funcionamiento y reglamentación de la actividad diplomática y consular y con ciertos temas de derecho internacional, tales como la extradición o las leyes de extranjería.

Otro rubro importante reúne textos sobre convenios amistosos con otros países, reclamaciones públicas y privadas por invasiones de los indios nómadas, pago de la deuda y contratos con particulares.

El tono de los escritos varía clel predominio de la sátira política a la solemnidad y a la alerta y preocupación por el estado de emergencia; pasa del discurso inflamado y patriota al optimismo en la defensa de la causa nacional, o recurre al elogio y a la esperanza en las soluciones provenientes del exterior. 
A continuación veamos las características en cada uno de los cortes tem. porales propuestos:

\section{1-1836}

En este periodo, uno de los objetivos de lo que podríamos llamar la política exterior de México, entendida como el conjunto de decisiones y acciones que un Estado toma para establecer y desarrollar su conducta hacia los demás actores de la sociedad internacional, aunado a la sucesión de prácticas impulsadas para cuidar, más allá de sus fronteras, los intereses del país, fue exponer al mundo cual era la posición de México. Encontramos así, folletos en los que el Congreso se dirigía a todas las naciones, o donde la Junta Provisional Gubernativa se manifestaba. ${ }^{5}$ Asimismo, la Secretaría de Relaciones Interiores y Exteriores dejó varias ediciones de las Memorias en las que se recogieron los informes periódicos de las diferentes gestiones realizadas. ${ }^{6}$ Por su parte, otras instancias gubernativas difundieron numerosas circulares en las que comunicaban decretos o hacían precisiones a los mismos.

Pero, sin duda, el tema fundamental de la folletería de este periodo se refiere a la amenaza ante el posible intento de reconquista española y a la situación con España. En la base existen, por lo menos, 125 folletos al respecto, que incluyen tanto los que ha-

\footnotetext{
5 II Supremo; 1821, y Manifiesto, 1821.

o Con excepción de 1824,1834 y 1836 , están reunidas todas las Memorias de 1821 a 1836.
}

blan de la defensa de San Juan de Ulúa (24) como aquellos que hacen un recuento de los preparativos de las expediciones contra la América Septentrional (40). Curiosamente, el número de folletos que abordan el asunto del reconocimiento a la independencia es significativamente menor (nueve) en una colección que, bajo el tema Política exterior, contiene 432 títulos en una muestra total de 7167 para los tres lustros. Hay otros folletos en los que se daba a conocer la posición real y la de las cortes españolas frente a la independencia americana.

A diferencia de otros periodos, en éste la sátira política fue muy utilizada (61 folletos) para expresar el rechazo a la política española y a su resistencia a reconocer al México independiente. Con pseudónimos como "Tirso Tarugo", "El Liberal Socarrón", "El Imparcial", "El Payo del Rosario"; con nombre y apellido como José Joaquín Fernández de Lizardi, o anónimos, se imprimían, en una o varias partes, títulos como $A$ ver si pegaba pero no pegó. Porque ya di basca gobiemo español; 7 A Fernando y Agustín les tocaron el violin ${ }^{8}$ Ya no quieren las gallinas que las manden los coyotes; ${ }^{9}$ El duende español del cementerio, o verdades desnudas caiga quien cayere ${ }^{10} O$ se destierra el coyote o mata nuestras gallinas; ${ }^{11}$ Fuera do-

7 "Tirso Tarugo", A ver, 1822.

8 "Liberal Socarrón", Fernando, 1823.

9) "El Imparcial", Ya no, 1824.

10 Villavicencio, Duende, 1823. Por cierto, este autor fue uno de los más prolificos del periodo, seguido por Joaquín Fernández de Lizardi.

11 Villavicencio, $O$ se destierra, 1824. 
nes y galones y títulos de Castilla; ${ }^{12}$ La correa de Juan de España que tiene al indio sin blanca; ${ }^{13}$ ¿A que no ronca el de Vlúa, con un Agustín al frente?, ${ }^{14}$ etcétera.

En cuanto a los vínculos con España o Inglaterra, la sátira política fue usada para expresar opiniones diversas acerca de lo que convendría más al país; así, encontramos De coyote a perro inglés, voy al coyote ocho a tres y Defensa de un gachupín quequieren arcabucear ${ }^{15} \mathrm{o}$ incluso se recurrió a ella para denunciar, entre otras formas, al enviado estadunidense Joel $\mathrm{R}$. Poinsett. ${ }^{16}$

La folletería de esos años recogió discusiones en torno a temas jurídicos como el derecho de gentes, los derechos de los extranjeros, o las implicaciones de contratar deuda en el exterior, y circularon también pequeños textos en los que se exponían asuntos consulares y diplomáticos, en relación con el tratamiento a extranjeros, de beres de los españoles residentes en el territorio de la federación, la expedición de pasaportes, la regulación del comercio extranjero, el nombramiento de ministros plenipotenciarios, ${ }^{17}$ la expulsión de españoles (y sus excepciones),${ }^{18}$ los planes de colonización extranjera en Baja California (de 1827),

12 Fernández de Lizardi, Fuera, 1823.

13 "D. P.", Correa, 1822.

1. Anónimo, A que no, 1822.

15 Villavicencio, De coyote, 1825, y Fernández de Lizardi, Defensa, 1825.

16 "El Capitán Cócora", Capitán, 1827.

17 Nombramiento, en 1824, de Mariano Michelena como ministro en Inglaterra.

${ }^{18}$ La cantidad de folletos sobre el tema permiten reflexionar sobre las leyes de expulsión. los tratados firmados con otros países (Colombia, en 1823; Gran Bretaña e Irlanda, en 1826; de demarcación de límites con Estados Unidos, en 1828; de Amistad, Comercio y Navegación con Dinamarca, Hannovery los Países Bajos, en 1829, con Estados Unidos de América, en 1831 y con Sajonia, Chile y Perú, en 1833), y la agregación de la provincia de Chiapas a México (en 1832).

La preocupación por asuntos internacionales, como los procesos políticos en otras naciones, Francia o lispaña por ejemplo, o de América del Sur y Centroamérica (Colombia, San Salvador, Perú, Guatemala, Chile, Argentina) ${ }^{19}$ estuvo presente desde los pri. meros años de vida independiente.

En un rubro distinto se publicaron ejemplares de la Constitución estadunidense con discursos de Washing. ton, ${ }^{20}$ de los Tratados entre España y los Estados Unidos de América del Norte, ${ }^{21}$ el Proyecto de Constitución para la República de Bolivia, ${ }^{22}$ de la conducta política estadunidense hacia las nuevas repúblicas americanas ${ }^{23}$ y otros acerca de las relaciones con la Santa Sede, el estado de la mincría y las posibles inversiones extranjeras (especialmente inglesas).

Tema aparte lo constituye la producción de textos dedicados a la regu-

${ }^{19}$ Edición que queremos resaltar no sólo por el tema, sino porque es la primera impresión que encontramos - en la base- de Ignacio Cumplido, una de las imprentas más importantes del siglo pasado. Pacheco, Revolución, 1835.

${ }^{20}$ Congreso de Estados Unidos, 1823.

${ }^{21}$ Onís, Memoria, 1826.

22 Bolivar, Proyecto, 1826.

23 Poinsett, Exposición, 1827. 
lación del servicio exterior, que se inició en $1829^{24}$ con el reglamento para las legaciones y consulados en el extranjero y al que se le sumaron un decreto sobre consulados de 1834 y el Reglamento de uniforme para el cuerpo diplomático mexicano, al año siguiente. ${ }^{25}$

Casi para cerrar el periodo, en 1835 aparecieron los primeros folletos que abordaron los asuntos de Texas, incrementándose su número en los meses posteriores.

En cuanto a las casas impresoras, los registros contenidos en la base nos permiten afirmar que hubo algunas muy activas, como la de Mariano Ontiveros ( 53 folletos), ${ }^{26}$ y la de Alejandro Valdés ( 27 folletos), ${ }^{27}$ que publicaban tanto textos satíricos como serios, polémicos o juridicos. Hubo, además, una gran cantidad de imprentas, entre las que podemos citar la Imprenta Contraria al Despotismo de J. M. Benavente, ${ }^{28}$ la de José María Ramos Palomera, la Oficina de doña Herculana del Villar y socios, la Im-

${ }^{24}$ Según los folleto incluidos en la base. Sin embargo, el dato podría variar de acuerdo con otra documentación.

25 Véase Decreto, 1829; Decreto, 1834, y Reglamento, 1835.

${ }^{26}$ Entre las publicaciones que aparecen como Oficina de Mariano Ontiveros, Oficina del finado Ontiveros y de la Testamentaria de Ontiveros. La cifra corresponde solamente a este primer periodo.

27 Considerando las publicaciones que aparecen como Imprenta Imperial de Alejandro Valdés, Imprenta a cargo de Alejandro Valdés, Imprenta de Alejandro Valdés y a cargo de José María Gallegos. La cifra corresponde al primer periodo analizado.

${ }^{28}$ Más tarde denominada de J. M. Benavente y socios. prenta del Águila dirigida por José Ximeno, la de la Escalerilla (que pervivió durante casi todo el siglo) y la de la Ex Inquisición a cargo de Manuel Ximeno, etcétera. Algunas publicaron más en los primeros años de vida independiente y después disminuyeron su participación o desaparecieron, como la Imprenta Americana de José María Betancourt, que ya no publicó después de 1822 .

Por otra parte, las dependencias gubernamentales tenían sus propias imprentas, como en el caso de la Secretaría de Relaciones Interiores y Exteriores $^{29}$ (que imprimía las memorias, tratados, circulares, reglamentos); la Secretaría de Hacienda (que publicaba sus circulares); la Secretaría de Guerra y Marina o el Ministerio de Justicia e Instrucción Pública. Había un sello del Congreso, ${ }^{30}$ otro del gobierno (la Imprenta Nacional del Supremo Gobierno en Palacio aparece solamente como gobierno) ${ }^{31}$ y en ciertos casos, el material se derivaba a casas impresoras particulares. ${ }^{32}$

29 En total, de acuerdo con los registros de la base, publicó como Secretaría de Relaciones Interiores y Exteriores 34 folletos en el primer periodo. A veces, publicaba en la Imprenta del Águila o en la del Estado en palacio a cargo del C. J. M. Infante. En el segundo periodo publicó 18 folletos.

${ }^{30}$ La base contiene ocho títulos para el primer periodo y otros ocho para el segundo.

${ }^{31}$ Se encuentran en la base 27 folletos para el primer periodo. Publicaba entre otros documentos los Tratados de Amistad, Comercio y Navegación, por ejemplo, con Dinamarca y los Países Bajos.

32 Como la oficina de D. Pedro de la Rosa, impresor del gobierno de Puebla o la Imprenta de Santiago Pérez (véase como ejemplo, Ador: no, Dictamen, 1835). 


\section{$1837-1851$}

Para este periodo la temática cambió hacia la cuestión texana (36 folletos de 237), las reclamaciones y el bloqueo francés (29), la correspondencia con el gobierno estadunidense (a partir de 1842), las reclamaciones de ciudadanos estadunidenses (siete) y la guerra con el vecino del norte (68, desde 1846).

Se imprimieron y difundieron el Tratado definitivo de Paz y Amistad con S. M. Católica (1838), los discursos de las autoridades dirigidos a la ciudadanía ante la agresión extranje$\mathrm{ra}$, los llamados a armar a la nación frente a la invasión y, por último, el Tratado de Paz con Francia (1840).

Los temas relacionados con los derechos y limitaciones para los extranjeros siguieron vigentes; así mismo, continuaron las publicaciones de los Tratados de Amistad, Comercio y Navegación de México (con las ciudades hanseáticas, 1842; con Austria, 1843); para la abolición del tráfico de esclavos (con S. M. Británica, 1843); entre países latinoamericanos (Brasil y Argentina, 1845), y hubo una que otra publicación sobre la deuda exterior y los proyectos de colonización. Las Memorias oficiales en las que se reseñaba la actividad del gobierno en el ámbito internacional, se publicaron regularmente, a excepción de los años $1840,1846-1848$ y 1851 .

En este periodo ya no encontramos el uso de pseudónimos o de la sátira en los folletos. Un número considerable de ellos no tiene pie de imprenta o fueron publicados en el exterior. La presencia de Ignacio Cumplido empie- za a tomar fuerza (encontramos 18 folletos) y a competir con la de José Mariano Fernández de Lara (20 folletos). También trabajaban de manera eficiente la Imprenta del Águila dirigida por José Ximeno (diez) y la de Vicente García Torres (once), al lado de otras que publicaron un menor número de títulos. No encontramos ningún trabajo de las prensas de $M$. Ontiveros, imprenta que había sido la más dinámica del periodo anterior.

La Secretaría de Relaciones Exteriores o Ministerio de Relaciones Exteriores, ya fuera bajo su sello o del de alguna imprenta particular, continuó publicando acerca de los temas que afectaban el interés nacional.

\section{$1852-1867$}

Hacia mediados de siglo surgieron nuevos hechos que acapararon la atención del público: la intervención francesa (46 folletos), el ofrecimiento de la corona mexicana al archiduque Maximiliano de Austria ${ }^{33}$ y el establecimiento del imperio (23). En los textos se expresan las posiciones, tanto de los partidarios de Francia y de sus planes $^{34}$ como de los defensores de México. ${ }^{35}$ Encontramos ejemplos que ofrecen la perspectiva que presentaron los debates al respecto en otros países, las intenciones extranjeras de

${ }^{33}$ La mayoría de la pluma de José María Gutiérrez de Estrada, y uno del historiógrafo del Imperio don $\mathrm{J}$. Rafael de Castro.

${ }^{34}$ Plancarte, Voto, 1863.

35 Extranjeros y nacionales. Entre los primeros, véase Gagern, Apelación, 1862. 


\section{SECUENCIA}

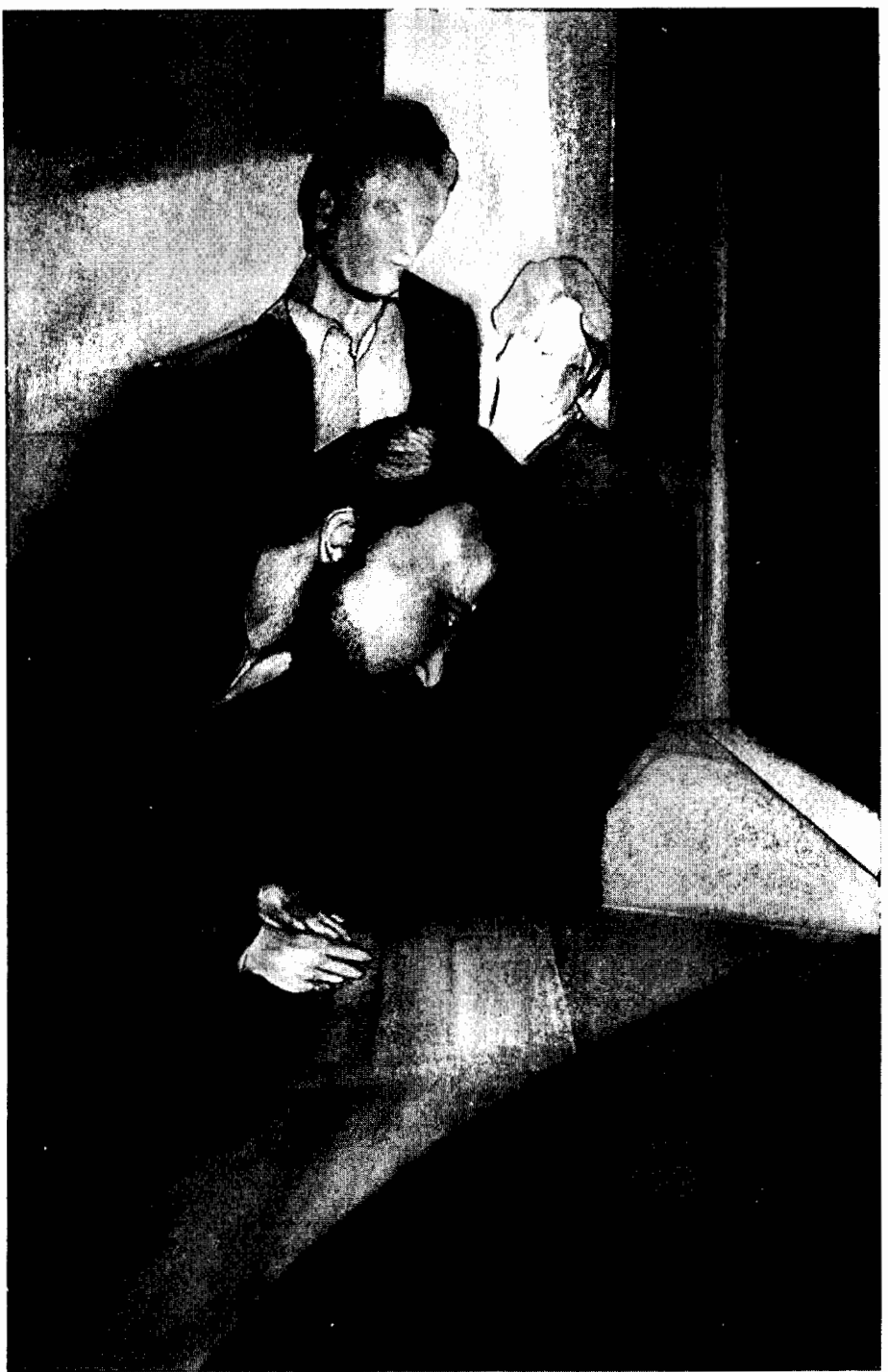

Ilustraciones de Adrián Bellón Pérez. Queda estrictamente prohibida la reproducción total o parcial de las imágenes publicadas en este número de la revista Secuencia, 39.

Las imágenes fueron contratadas y/o donadas de forma exclusiva para esta publicación. 
participar, ${ }^{36}$ así como la opinión de ciudadanos mexicanos. 37 Varios, incluso, analizaron la cuestión de la intervención y el imperio desde la perspectiva de los intereses de las potencias europeas. ${ }^{38}$

En una miscelánea de temas encontramos, por ejemplo, la importancia de la emigración alemana(porC. Sartorius), expediciones filibusteras (del conde Raousset de Boulbon), la deuda colombiana a México, los millones de la Mesilla y otros más significativos para la política exterior de México, como los documentos relativos a las convenciones diplomáticas que garantizaron el pago de la deuda española o las relaciones con Estados Unidos, sobre todo en cuanto a la defensa contra los indios bárbaros.

La apertura de una vía de comunicación por el istmo de Tehuantepec fue analizada por la Comisión de Asuntos Extranjeros del Senado estadunidense y por la Cámara de Diputados de México, publicándose sendos informes. El enviado extraordinario y ministro plenipotenciario en Washington, Manuel Larrainzar, también contribuyó a formar una opinión con sus reportes y envío de artículos publicados sobre la materia.

En el apartado que aborda la reglamentación de la conducta de México en los negocios con países extranjeros, encontramos la publicación de documentos sobre convenciones diplomáticas, así como reglamentos

\footnotetext{
${ }^{36}$ McDougall, Discurso, 1862.

37 Gitrcía, Intervención, 1863.

38 Passama, L'empire, 1866, entre muchos otros títulos.
}

europeos de emigración, las dificultades con España (guerra con ella y convención española); 39 Tratados de Amistad, Navegación y Comercio con otros países (Italia, 1855; Alemania y Cerdeña, 1856; Bélgica, 1862) e, incluso, una Tabla sinóptica de los tratados y convenciones firmados con las naciones extranjeras. En 1860 la cuestión del Tratado Mac Lane empezó a cobrar importancia y se publicaron algunos folletos en los que se expresaron las posiciones de gobiernos departamentales (como fue el calso de Guanajuato), Ayuntamientos (por ejemplo el de Hidalgo), o de algunos particulares (de Orizaba).

De este periodo, la base contiene un gran número de folletos publicados en el exterior, principalmente por casas francesas ( 33 folletos). De las mexicanas sobresale la labor de la imprenta de Víctor García Torres (19) y la de Ignacio Cumplido (doce). La de la Secretaría de Relaciones lixteriores, que incorporó a Gobernación, siguió publicando, pero la base sólo tiene registrados siete títulos.

\section{$1868 \cdot 1880$}

En este periodo hay tres temas fundamentales en el reducido número de folletos (50):

1. Cuestiones relacionadas con isuntos económicos (como la convención es-

\footnotetext{
39) Cuestión en la que se manifiestan las opiniones mexicanas y las españolas, incluida una del general Prim donde cuestiona la actuación de España: Prim, Discurso, 1863.
} 
pañola, las actividades de la Comisión de Finanzas de México, el establecimiento de una zona libre en la frontera de Tamaulipas, la deuda extranjera, las reclamaciones de los tenedores de bonos).

2. La definición de las fronteras, rubro en el que se incluyen folletos acerca de las reclamaciones de ciudadanos estadunidenses y mexicanos (referidas primordialmente a las incursiones de los indios nómadas y a las depredaciones causadas por ellos) y la cuestión de límites entre México y Guatemala.

3. La normatividad para regular las actividades en el exterior: reglamento del cuerpo consular, establecimiento de una legación en América del Sur, opiniones en torno a la jurisprudencia en el juicio de extradición y la publicación de los Tratados de Amistad, Comercio y Navegación (con Italia, 1870).

La casa impresora más activa fue la del gobierno (con quince folletos), ${ }^{40}$ seguida por Ignacio Cumplido (cuatro) e I. Escalante (cuatro).

\section{$1881-1892$}

Continúa puntualizándose la cuestión de los límites de México, por una parte con el vecino del norte, pero de manera sobresaliente con Guatemala. Al reanudarse las relaciones con algunos países, se puso especial cuidado en publicar los Tratados de Amistad, Comercio y Navegación (con el imperio alemán, 1883), el tratado con Guatemala (1883); un cuadernillo que daba

(1) Ya sea que aparezca como Imprenta del Gobierno, Imprenta del Gobierno en Palacio, a cargo de J. M. Sandoval o de Sabás A. y Munguía. cuenta del inicio de las conversaciones con Gran Bretaña en 1884, otros que reseñaban la firma de tratados con España (1886), con Ecuador (1890), con Italia (1891) y con la República Dominicana (1891).

El tema de la extradición, abordado en épocas anteriores, fue retomado y se hicieron varias publicaciones al respecto. Paralelamente, se imprimió una ley sobre extranjería y naturalización.

En este periodo-y siempre de acuerdo con los datos que ofrece la base-la actividad oficial se incrementó, de la Secretaría de Estado y Despacho de Relaciones Exteriores encontramos catorce folletos, en comparación con cinco del periodo anterior. También hubo varias publicaciones del Congreso y, en menor número, de las Secretarías de Gobernación, Hacienda y Fomento.

\section{$1893-1910$}

De todo el periodo considerado, la producción de folletos referentes a asuntos de política exterior fue mínima en este último segmento, sólo encontramos 29 en un total que asciende a cerca de 4204.

La precisión en la cuestión de límites fue un tema recurrente en esos años. Se concedió gran importancia, también, al debate en torno a la Doctrina Monroe, que fue abordado tanto en la prensa como en los folletos. ${ }^{41}$

En los primeros años del siglo $\mathrm{xx}$ aparecieron algunas publicaciones relacionadas con el establecimiento de

41 Zaragoza, Monroísmo, 1896. 
vínculos comerciales con Japón. En cuanto a los temas jurídicos relacionados con el desempeño diplomático se trataron, por ejemplo, la extradición y las leyes de inmigración.

\section{MÉXICO Y EL CARIBE}

Como hemos visto, los folletos constituyen ricas y apreciables fuentes documentales para investigar en diversos temas de la política exterior. De la amplia muestra recolectada, dedicaremos ahora unas palabras a los que se refieren a los vínculos con el Caribe.

Desde la perspectiva mexicana del siglo XIX, el Caribe estaba formado por las Antillas y el mar circundante, es decir, se hacía referencia exclusivamente a la región insular. En ese entonces no se consideraba a la zona del litoral, excepción hecha de Belice (que fue, hasta la segunda mitad del siglo, una dependencia de Jamaica y que constituye la única frontera terrestre con la región), como parte de lo que hoy se conoce como la cuenca del Caribe.

En los primeros años de vida independiente, uno de los principales temores del joven país era que España intentase reconquistar sus antiguas posesiones americanas utilizando a Cuba para organizar a sus ejércitos. ${ }^{42}$ Por eso, una de las primeras tareas emprendidas fue apoyar la emancipa-

\footnotetext{
${ }^{42}$ A este temor responde la publicación de folletos como el de José Ma. Morón previniendo a los mexicanos de una posible invasión española para reconquistar los territorios que otrora fueron de España, Puebla, 1823.
}

ción de la isla como una manera de asegurar la propia soberanía. Gran parte de la documentación que se refiere al tema, lo aborda desde la perspectiva optimista y resaltando la actitud de apoyo mexicano. En ella no se percibe que hubiera habido sectores que no estuvieran de acuerdo con tal proyecto. Sin embargo, al parecer tal esfuerzo fue cuestionado en ciertos círculos y esto podemos saberlo a través de un folleto escrito por Pablo de Villavicencio, "El Payo del Rosario", en el que encontramos la argumentación para rechazar el envío de tropas a la Gran Antilla. ${ }^{43}$

En medio de las opiniones que aseveraban que no había cosa más justa y conveniente para la seguridad nacional que intervenir en favor de la independencia cubana equipando "una escuadrilla de diez a quince mil hombres bien pagados y con pertrechos suficientes", ${ }^{44}$ y que debían unirse a las fuerzas colombianas para consumar la victoria, "El Payo del Rosario" señalaba:

No tienes para calzones y quieres peso ajustado[...] No hemos podido rendir el castillo en cuatro años y ya queremos ir a conquistar a otros países distantes [...] La escuadra que ustedes dicen, estaría mejor empleada bloqueando el castillo que es el enemigo más cercano y más fácil de rendir, cuya obra sólo consiste en impedirle la entrada de víveres $[\ldots]$ y esto sin exponer los buques a los fuegos de los baluartes, lo que no podía suceder con el bloqueo de La Habana. ${ }^{45}$

43 Villavicencio, Si van, 1825.

44 Ibid., p. 6.

45 Ibid. 
En su exposición resaltaba, además de la dificultad de hacer la guerra desde el mar sin protección, con gran desventaja respecto a las fuerzas españolas estacionadas en la isla, la imposibilidad de obtener recursos o de alcanzar el apoyo de la población del interior de la misma, que se encontraba escindida en facciones políticas y sectores sociales.

El recelo oficial hacia la permanencia de Cuba como colonia española, sin embargo, no era infundado. España podía aprovechar su posición en la isla y utilizarla como base para concretar sus intentos de reconquista, como efectivamente lo hizo con la expedición que comandó el brigadier Isidro Barradas, que salió de La Habana en $1829^{46}$ y sobre la que hay muchos folletos. Aun después de la derrota de Barradas continuó el temor ante la pretensión española, según quedó de manifiesto por la gran cantidad de folletos publicados después del fracasado intento en las costas de Tampico. ${ }^{47}$

Para las autoridades mexicanas todo el litoral era considerado zona de defensa de la seguridad nacional, y cualquier acontecimiento era informado $y$ tomado en cuenta, como por ejemplo la entrada de españoles en el puerto de Sisal. ${ }^{48}$

Después de la firma del Tratado de Paz con España, mediante el cual se reconocía la independencia de Méxi-

46 Guerrero, Presidente, 1829.

47 Alamán, Circular, 1830, publicada también por la Secretaria de Relaciones Interiores y Exteriores. Véase, también, Cabildo Metropolitano, Circular, 1833.

${ }^{48}$ Gaceta, 1829. co, la desconfianza ante la posible reconquista desapareció, y el interés de nuestro pais en relación con la zona caribeña se volcó al fomento de las actividades mercantiles que dejaban, en los puertos habilitados en el Golfo, una importante cantidad de recursos en los que se sustentaba en gran medida el erario nacional. A México le interesaba, pues, mantener despejadas las rutas comerciales y que el intercambio mercantil se llevara a cabo, en su mayoría, dentro de los límites de la legalidad. Dos ejemplos en los que se refleja esta preocupación se encuentran en sendos folletos, uno que aborda la cuestión del contrabando realizado por embarcaciones inglesas en las costas de la península yucateca, ${ }^{49}$ y otro acerca de la importancia y necesidad de proteger una marina mercante mexicana, que aconsejaba la imposición de medidas arancelarias y disponía, para los barcos españoles, el pago de cuotas equiparables a las que sancionaban el tráfico realizado en embarcaciones mexicanas y depositado en los puertos de Cuba, Puerto Rico y Jamaica ${ }^{50}$ Aquí pareciera que se combinan en la argumentación los intereses particulares con los gubernamentales, en la defensa de la construcción de una marina mercante nacional. Se proponía que "el comercio de la isla de Cuba con nuestros puertos se [hiciera] exclusivamente bajo nuestro pabellón o se [repartiera] por lo menos

49 Comunicaciones, 1829.

50 Véase, Justos, 1849. Asunto tratado, por cierto, por el cónsul mexicano en la l Iabana, Buenaventura Vivó, según recuerda en sus Memorias. 
entre nuestra marina mercante y la de la nación española". 51

De la época de la guerra mexicanoestadunidense queremos resaltar la publicación del Reglamento para el corso de particulares contra los enemigos de la nación,${ }^{52}$ con varias ediciones, porque tuvo su principal aplicación en la región del Golfo-Caribe, y uno de los más activos promotores de su cumplimiento fue el cónsul mexicano en La Habana, don Buenaventura Vivó. ${ }^{53}$ Se buscaba constituir un instrumento auxiliar en la guerra contra Estados Unidos "para debilitar al enemigo" mediante la providencia de establecer corsarios que perjudicaran su comercio.

El Golfo-Caribe, como escenario de las acciones que amenazaban la integridad territorial y las reacciones que la defendían, aparece en una gran cantidad de folletos que se refieren a los bloqueos a Veracruz, los desembarcos en puntos importantes del litoral y a las maniobras y componendas de las facciones políticas. ${ }^{54}$

En el periodo de 1868-1880, y como signo de las nuevas preocupaciones del gobierno mexicano orientadas a fomentar sus relaciones con sus vecinos tenemos el folleto Informe de las relaciones mercantiles de la república con la isla de Cuba presentado a la Secretaría de Fomento ${ }^{55}$ y, como

${ }^{51}$ Justos, 1849, pp. 26-27.

52 México, ministro de Guerra y Marina, $R e$ glamentos, 1846. Aparece también como Paredes, Reglamento, 1846,20 p. y Ministerio de Guerra y Marina, Reglamento, 1846.

53 Véase Pfandl, "Cónsules", 1997.

54 Por ejemplo, véase Carta, 1850.

55 Crespo, Informe, 1884. muestra del interés por ocupar todo el territorio, los folletos, que a partir de 1878 informan de las negociaciones y tratados de límites México-Belice, ${ }^{56}$ y otros que expresan la agresiva presencia estadunidense, como el escrito acerca de la disputa por la isla de Arenas, ${ }^{57}$ en el que se manifiesta una preocupación real ante el avance estadunidense que el autor explica en los siguientes términos:

Si una potencia extranjera llegara a ser definitivamente la poseedora de Cayo Arenas, ella tendría un pleno dominio sobre toda la península yucateca, pues siendo ésta la parte más oriental de la república, que avanza entre el Golfo de México y el mar de las Antillas, esa potencia no se apoderaría del miscrable cayo situado en dicho golfo, sino para dominar enseguida sobre la península $y$, por lo tanto, para aprender a toda la república $[. . .]^{58}$

Pero el autor coloca esa posibilidad y sus repercusiones en un ámbito más amplio y dice:

Esta situación demuestra la importancia geográfica de Yucatán, porque si un gran poder marítimo, dueño ya de la Florida, extiende como un coloso su planta sobre el cabo Catoche, no hay duda que pronto, estrechando a Cuba entre sus brazos, sería dueño de la entrada y, por lo tanto, del comercio del Seno mexicano. 59

56 Peniche, Historia, 1869; Scholl, Belize, 1878; SRE, Correspondencia, 1878 (la misma casa editorial imprimió una versión en francés).

57 Carrillo, Isla, 1886.

58 Ibid., p. 1.

59 rbid. 
La polémica siguió varios años, y la Secretaría de Relaciones Exteriores mandó imprimir la correspondencia que intercambió con el gobierno de los Estados Unidos de América y en la que defendía su soberanía sobre esos territorios. ${ }^{60}$

En la última década del siglo, la región caribeña readquirió importancia para el gobierno mexicano. Se fortalecieron los vínculos con las islas y se reactivó el establecimiento de oficinas consulares en sus territorios. En la folletería quedó registrado que, en 1891, se firmó un Tratado de Amistad y Comercio con la República Dominicana $^{61} y$, posteriormente, otro entre Yucatán y Belice. ${ }^{62}$ Además, se publicaron varios textos que abordaban la cuestión del establecimiento de límites con esa colonia inglesa, así como un folleto en el que se analizaba, en el terreno práctico y desde el punto de vista constitucional, el tratado firmado con S. M. británica. ${ }^{63}$

Un tema de importancia en los días finiseculares fue la posición mexicana ante la cuestión cubana. Entre las muchas publicaciones que hubo en esos años, encontramos una historia de la guerra de $\mathrm{Cuba}^{64}$ y una recopilación de artículos enviados al Diario de la Marina, que circulaba en La Habana, en los cuales se exalta la simpatía mexicana por España. El autor es un simpatizante del hispanoamericanismo que se desarrolló en esos años como una

\footnotetext{
60 SRE, Cayo, 1895.

61 SRl, Tratado, 1891.

62 Mariscal, Informe, 1893.

63 Gutiérrez, Trato, 1894.

${ }^{64}$ Ramos, Apuntes, 1896.
}

doctrina que uniría a los pueblos de América Latina para que, apelando a su identidad y tradición cultural hispánica, enfrentaran la amenaza estadunidense. ${ }^{65}$ En resumen, el autor rescata un viejo planteamiento que señala que ante la disyuntiva de tener una Cuba española o una Cuba yanqui, México preferiría la primera opción, puesto que lo contrario "sería dar a los vecinos del norte la llave del Golfo, que es como quien dice la llave del zaguán. No: a México le conviene que Cuba no deje de ser española; mientras lo sea tendrá una vecina amiga[...]". ${ }^{66}$

Relacionados en cierta forma con este tema son los folletos El monroísmo y el general D. Porfirio Díaz, publicado en La Habana, ${ }^{67}$ y La neutralidad. Derechos y obligaciones de las naciones neutrales. 68

Considerando todos los títulos reunidos, podemos afirmar que, en el primer periodo, los folletos publicados en el litoral, o que hablan de él, así como los impresos en La Habana, se refieren a la invasión española, aunque con propósitos distintos. ${ }^{69}$ En el segundo periodo, el tema central es la presencia y la intervención extranjera. ${ }^{70}$

${ }^{65}$ Cuyas, Desde, 1895.

66 Ibid., p. 34.

67 Zaragoza, Monroísmo, 1896.

${ }^{68}$ León, Neutralidad, 1898.

69 Gobierno de Veracruz, Recapitulación, 1826; Gaceta, Palacios, Noticias, 1829. Mientras que los publicados en La Habana eran cantos a la expedición invasora: "J. B.", Canto a la expedición, 1829; "J.B.", Canto heroico, 1829; "J. B.", Epinicio, 1829.

${ }^{70}$ Baudin, $A$ bordo, 1838; López de Santa Anna, Manifiesto, 1837; Comunicaciones, 1841; Lafragua, El día, 1846; Garza, Estados Unidos, 1846. 
Del tercer periodo hay varios folletos publicados en el litoral Golfo-Caribe. La base contiene uno, publicado en Tabasco, que habla de los tratados firmados por México; ${ }^{71}$ otro en Nueva Orleans sobre la actuación de Miramón $;^{72}$ dos más acerca de la intervención en México, uno de La Habana y el segundo de Veracruz, ${ }^{73}$ y, finalmente, uno sobre la cuestión española publi. cado en Campeche. ${ }^{74}$

La preocupación por la frontera sur Ia encontramos manifestada en el cuarto periodo con las publicaciones acerca de Belice ${ }^{75}$ - que continúa hasta finales de siglo-, ${ }^{76}$ y el interés por fortalecer las actividades comerciales con Cuba y con la República Dominicana, en el siguiente periodo, ${ }^{77}$ en el que renace el discurso de defensa de la soberanía, no solamente como una preocupación del gobierno central, ${ }^{78}$ sino también de los particulares. ${ }^{79}$

\section{CONSIDERACIONES FINALES}

Para concluir, quisiéramos señalar que en los folletos se encuentra reflejada la historia política de México y los temas fundamentales de su vinculación con

${ }^{71}$ Romero, Tabla, 1859.

72 Cucullu, Verité, 1860.

73 Argüelles, Breves, 1863 , y Observaciones, 1863.

74 Prim, Discurso, 1863.

75 Véase nota 56.

76 Mariscal, Informe, 1893; Gutiérrez, Trato, 1894 .

77 Crespo, Informe, 184; SRE, Tratado, 1891.

${ }^{78} \mathrm{El}$ que en el siguiente periodo publicó: SRE, Cayo, 1895.

${ }^{79}$ Carrillo, Isla, 1886, y Pavía, Ingleses, 1888. el exterior. Las oficinas del gobierno fueron activas promotoras y difusoras de sus actividades y, paralelamente a los autores particulares, publicaron una importante cantidad de folletos.

El conjunto reunido da para hacer una reflexión general o para ahondar en temas específicos. No obstante, aunque son fuentes documentales de indudable riqueza, debe considerarse siempre cuales son sus alcances reales y sus limitaciones.

A partir del número de folletos recopilados, podemos afirmar que cada uno de los segmentos en los que se ha dividido todo el periodo, está marcado por uno o dos temas, iniciando con el de la posible reconquista española de México, la cuestión texana, el bloqueo francés, la invasión estaduniclense, la intervención francesa, etc., con lo cual se ratifica que, una de las principales preocupaciones en cuanto a política exterior, era la defensa del territorio y la preservación de la soberanía y la seguridad nacionales, amenazadas continuamente por las pretensiones de los poderes extranjeros.

La folletería nos ofrece la oportuniclad de conocer opiniones coincidentes o encontradas en cuanto a situaciones específicas que causaron alteración en su momento. Por ejemplo, la conspiración del padre Arenas, la expedición del brigadier Barradas, el imperio de Maximiliano, etcétera.

Uno de los temas fundamentales fue el de la presencia y la intervención extranjera y, por tanto, la noción de la frontera que resguarda. Otro tema constante en la documentación es el que se refiere a la reglamentación del funcionamiento de la Secretaría de Relacio- 
nes Exteriores y del servicio exterior mexicano.

\section{BIBLIOGRAFÍA}

-Adorno, Rafael y otros, Dictamen de la Comisión de Industria sobre la prohibi. ción de hilazas y tejidos de algodón [del extranjero. Presentado en la Cámara de Diputados el día 27 de marzo de 1835], Imp. de Santiago Pérez, México, 1835, 14 pp.

-Alamán, Lucas, Circular expedida en México el 17 de abril de 1830 por la primera Secretaría de Estado, a cargo de Lucas Alamán, pidiendo a los gobernadores de los estados a nombre del vicepresidente de la república, Anastasio Bustamante, que con motivo de que España prepara nueva invasión del país, todos.., Primera Secretaría de Estado, México, 1830, 2 pp.

-Anónimo, ¿A que no ronca el de Ulúa, con un Agustín al frente?, Oficina de José María Ramos Palomera, México, 1822.

-Argüelles, José Agustín, Breves apuntes sobre la historia de la intervención en México, Imprenta del Gobierno y Capitanía general, La Habana, 1863, 31 pp.

-Baudin, Carlos, $A$ bordo de la fragata de S.M. La Nereida. Sacrificios, 27 de octubre de 1838, Veracruz, 1838, 8 pp.

-Bolívar, Simón, Proyecto de Constitución para la República de Bolivia y discurso del libertador, Oficina del ciudadano Alejandro Valdés, 1826, 14 pp

-Cabildo Metropolitano, Circular del deán y Cabildo gobernador de la iglesia metropolitana de México. Alertando a la población contra los invasores españoles, México, 1833, 16 pp.

-Carrillo de Ancona, Crescencio, La isla de Arenas. Apuntes para la defensa de la integridad del territorio nacional, con relación a dicha isla y a otras muchas que con ella se enlazan en las costas de Yucatán, Mérida, 1886, 21 pp.

- Carta suscrita el 5 de marzo de 1850 a bordo delbuque de guerra inglés Valoreus surto en la bahía de Veracruz, por el capitán W. Cornwallis Aldham y destinada al ministro de Asuntos Extranjeros Santos Degollado, informándole que tuvo una entrevista con el general Miguel Miramón, Veracruz, 1850.

-Comunicaciones oficiales sobre el injusto reclamo de los comisionados del gobierno de Belice al del estado de Yucatán: por el apresamiento de la goleta inglesa mercante True Blue que, violando las leyes del país, hacía el contrabando en sus costas, Imp. J. D. Espinosa, México, 1841, 108 pp.

-Congreso de Estados Unidos, Imp. a cargo de Martín Rivera, México, 1823, 66 pp.

-Crespo y Martínez, Gilberto, Informe de las relaciones mercantiles de la república con la isla de Cuba presentado a la Secretaría de Fomento, Imprenta de la Sría. de Fomento, México, 1884, 65 pp.

-Cucullu, Joseph, La veritésur Miramon et les Etats Unis, Imp. Francoamericaine, Nueva Orleans, 1860, 44 pp.

-Cuyas, Arturo, Desde México: Cartas dirigidas al Diario de la Marina de La Habana, Ignacio Escalante, México, 1895, $95 \mathrm{pp}$.

-Decreto de 31 de octubre de 1829, sobre legaciones y consulados en el ex. tranjero, Gobierno, México, 1829, 4 pp.

- Decreto de 12 de febrero de 1834 sobre consulados en el extranjero, Congreso, México, 1834.

- Discurso del teniente general D. Juan Prim, conde de Reus, marqués de los Castillejos, sobre la cuestión de México, pronunciado en el Senado español en las sesiones del 9, 10 y 11 de diciembre de $1862 y$ contestación del mismo al Sr. Bermúdez de Castro en la sesión del día 20, Imp. de Peralta, Campeche, 1863. 
-D. P.", La correa de Juan de España que tiene al indio sin blanca, Imprenta de D. José Ma. Ramos Palomera, México, 1822, 4 pp.

-"El Capitán Cócora", El capitán Cócora contra el ministro Poinsett, Imprenta a cargo del ciudadano Uribe y Alcalde, Méxi$\mathrm{co}, 1827,8$ pp.

"El Imparcial", Ya no quieren las gallinas que las manden los coyotes, Oficina liberal a cargo del ciudadano Juan Cabrera, México, 1824, 4 pp.

-El supremo Congreso a todas las naciones, Congreso, México, 1821, 8 pp.

-Fernández de Lizardi, José Joaquín, Fueradones y galones y títulos de Castilla, Oficina Liberal a cargo del ciudadano Juan Cabrera, 1823.

,Defensade un gachupinque quieren arcabucear, Oficina de D. Mariano Ontiveros, México, 1825, 8 pp.

- Gaceta extraordinaria: entrada de los españoles en el puerto de Sisal, s.p.i., 1829,3 pp.

-Gagern, Carlos de, Apelación de los mexicanos a la Europa bien informada de la Europa mal informada, Imp. I. Cumplido, México, 1862, 86 pp.

-García Vargas, Miguel, La intervención francesa de la república de Méjico. Opúsculo escrito enjulio del presente año, Imp. Literaria, México, 1863, 30 pp.

-Garza y Evia, Juan N. de la, Los Estados Unidos sin otra razón de política que su fuerza y prepotencia han invadido el territorio de Tamaulipas, Monterrey, 1846.

-Gobierno de Veracruz, Recapitulación de varias alocuciones $y$ oficios de las autoridades de Veracruz. Discursos, composiciones poéticasyoración del Tribuno del Pueblo Veracruzano en los dias 23, 24 y 25 de diciembre de 1826, con motivo de celebrarse el primer aniversario de la rendición de Ulúa, Imprenta del Papaloapan a cargo de J. Parladorio, Veracruz, 1826, 40 pp.
-Guerrero, Vicente, Elpresidente de los Estados Unidos Mexicanos. Compatriotas: la expedición española que condirección de nuestras costas salió de La Habana el mes próximo pasado..., Imprenta del Águila, México, 1829, 4 pp.

-Gutiérrez González, Eduardo, El trato sobre Belice, Tip. El Libro Diario, México, 1894, 26 pp.

“J. B.", Canto a la expedición del señor Barradas, La Habana, 1829, 7 pp. , Canto heroico por la feliz arribada de la expedición de los señores don Ángel Navarroy don Isidro Barradas a las costas de Tampico. Dedicado al rey nuestro señor, La Habana, 1829, 6 pp. , Epinicio al felizéxito que ha tenido la expedición del señor Barradas en las costas de Nueva España. Dedicado a la nación española, La Habana, 1829, 6 pp.

-Justos reclamos por el modo en que se trata a los buques mexicanos en las islas de Cuba y Puerto Rico: se indica el remedio de ese mal y se proponen con tal motivo varias providencias importantes, de conformidad con los tratados vigentes, para proteger la marina mercante de la república todo por los IE. del Globo $y$ estandarte mejicano, Imp. de Lara, México, 1849, 59 pp.

-Lafragua, José María, El día 14 del corriente fue ocupado el puerto de Tampico por los americanos, México, $1846,3 \mathrm{pp}$.

-León de la Barra, Francisco, La neutralidad. Derechos y obligaciones de las naciones neutrales, Tip. de T. González Sucs., México, 1898, 20 pp.

"Liberal Socarrón", A Fernando y Agustín les tocaron el violín, Imp. de Herculana del Villar y socios, México, 1823, 24 pp.

-López de Santa Anna, Manifiesto que de sus operaciones en la campaña de Texas y en su cautiverio dirige a sus conciudadanos el general..., Veracruz, $1837,948 \mathrm{pp}$. 
-Manifiesto de la Junta Provisional Gubernativa al público del imperio, Imprenta Imperial de Alejandro Valdés, México, 1821, 4 pp.

-Mariscal, Ignacio, Informe del C. Ignacio Mariscal, secretario del Despacho de Relaciones Exteriores, rendido ante el Senado acerca del Tratado de Límites entre Yucatán y Belice, Imprenta de F. Díaz de León, México, 1893, 55 pp.

-McDougall, M., Discurso pronunciado en el Senado de los Estados Unidos apoyando las proposiciones que presentó para que la república del norte auxilie a México en la actual guerra con Francia, Imp. de V. G. Torres, México, 1863, $71 \mathrm{pp}$.

-México, Ministerio de Guerra y Marina, Reglamento para el corso de particulares contra los enemigos de la nación, 1846, 20 pp.

-Ministerio de Guerra y Marina, Reglamento para el corso de particulares en la presente guerra, Imprenta del Águila, México, 1846, 2 pp.

- Observaciones a la carta que D. Manuel Payno ha dirigido al Sr. gral. Forey, Veracruz, $1863,30 \mathrm{pp}$.

-Onís, Luis de, Memoria sobre las negociaciones entre España y los Estados Unidos de América, que dieron motivo al tratado de 1819, con una noticia sobre la estadística de aquel país, Oficina a cargo del ciudadano Martín Rivera, México, 1826, $60 \mathrm{pp}$.

-Pacheco, José Ramón, Una revolución en la república argentina. Artículo de la Revista de los Dos Mundos, Ignacio Cumplido, México, 1835, 26 pp.

-Palacios, Mariano, Noticias de Tampico, Puebla, 1829, 3 pp.

Paredes y Arrillaga, Mariano, Reglamento para el corso de particulares contra los enemigos de la nación, Imprenta del Conejo, México, 1846, $20 \mathrm{pp}$.

-Passama Domenech, J., L'empire mexicain, la paix et les intéréts du mon- de, Imp. de I Cumplido, México, 1866, 97 pp.

-Pavía, Lázaro, Los ingleses en México o sea el origen y fundación de las colonias británicas en el Seno mexicano, Imp. de José V. Castillo, México, 1888, 24 pp.

-Peniche, Manuel, Historia de las relaciones de España y México con Inglaterra, sobre el establecimiento de Belice, Imprenta del Gobierno, México, 1869, 71 pp.

-Pfandl, Ludwig, "Los cónsules mexicanos en La Habana; su visión geopolítica y la defensa del interés nacional", $2^{2}$ Conferencia de las Américas, Universidad de las Américas, Cholula, Puebla, febrero 1997.

-Plancarte, Gabriel, Voto en favor de la intervención de la nación francesa en la república de los Estados Unidos Mexicanos, Tipografia de Rivera, Puebla, 1863, 8 pp.

-Poinsett, Joel R., Exposición de la conducta política de los Estados Unidos para con las nuevas republicas de América, Imprenta de la Ex Inquisición a cargo de Manuel Ximeno, México, 1827, 16 pp.

-Prim y Prats, Juan, Discurso del teniente general D... conde de Reus, marqués de los Castillejos, sobre la cuestión de México pronunciado en el Senado español en las sesiones del 9, 10 y 11 de diciembre de 1862 y contestación del mismo al Sr. Bermúdez de Castro en la sesión del día 20, Imprenta de Peralta, Campeche, 1863, 78 pp.

-Ramos Duarte, A. (editada por Lázaro Pavia), Apuntes para la historia de la guerra de Cuba, Imprenta Eduardo Dublán, México, 1896, 43 pp.

-Reglamento de uniforme para el cuerpo diplomático mexicano, Secretaría de Relaciones Interiores y Exteriores, México, 1835, 2 pp.

-Romero, Matías, Tabla sinóptica de los tratados y convenciones que han negociado los Estados Unidos Mexicanos con las naciones extranjeras, Tip. del 
Gobierno a cargo de J. M. Flores, Tabasco, 1859,78 pp.

-Scholl, C., Belize (British Honduras). Diplomatic correspondence between her britanic Majesty's government and the government of the republic of Mexico, Liverpool, 1878, $78 \mathrm{pp}$.

-SRE, Cayo Arenas y otras islas guaneras en los mares de Campechey Yucatán. Correspondencia entre los gobiernos de México y los Estados Unidos de América acerca del dominio sobre dichas islas, Imprenta del Gobierno del Ex Arzobispado, México, 1895, 64 pp.

Correspondencia diplomática entre el gobierno de la república y el de su majestad británica con relación al. territorio llamado Belice (1872-1878), Ignacio Cumplido, México, 1878, 94 pp. Tratado de amistad y comercio con la República Dominicana, México, 1891, 17 pp.

"Tirso Tarugo", A ver si pegaba pero no pegó. Porque ya di basca gobierno español, Oficina de José Ma. Ramos Palomera, México, 1822, 4 pp.
-Villavicencio, Pablo de, "El Payo del Rosario", El duende español del cementerio, o verdades desnudas caiga quien cayere, Imprenta de D. Mariano Ontiveros, México, 1823, 8 pp. , $O$ se destierra el coyote o mata nuestras gallinas, la. parte, Imp. de D. Mariano Ontiveros, México, 1824, 7 pp.; 2a. parte, Oficina Nacional y de Gobierno, Puebla, 1824, 8 pp. De coyote a perro inglés voy al coyote ocho a tres, Oficina liberal del ciudadano Juan Cabrera, 1825, 8 pp. Si van tropas a La Habana, nos hacen aqui la fiesta. Conclusión del sueño del "Payo del Rosario", comenzado en el impreso titulado: El gallo se halla durmiendo y los coyotes velando, que salió de la casa del finado Ontiveros, Oficina de D. Mariano Ontiveros, México, 1825, 12 pp.

-Zaragoza y Escobar, Antonio, El monroísmo y el general don Porfirio Diaz, Imp. El Comercio Tipográfico, México, La Habana, 1896, 66 pp. 


\section{SECUENCIG}

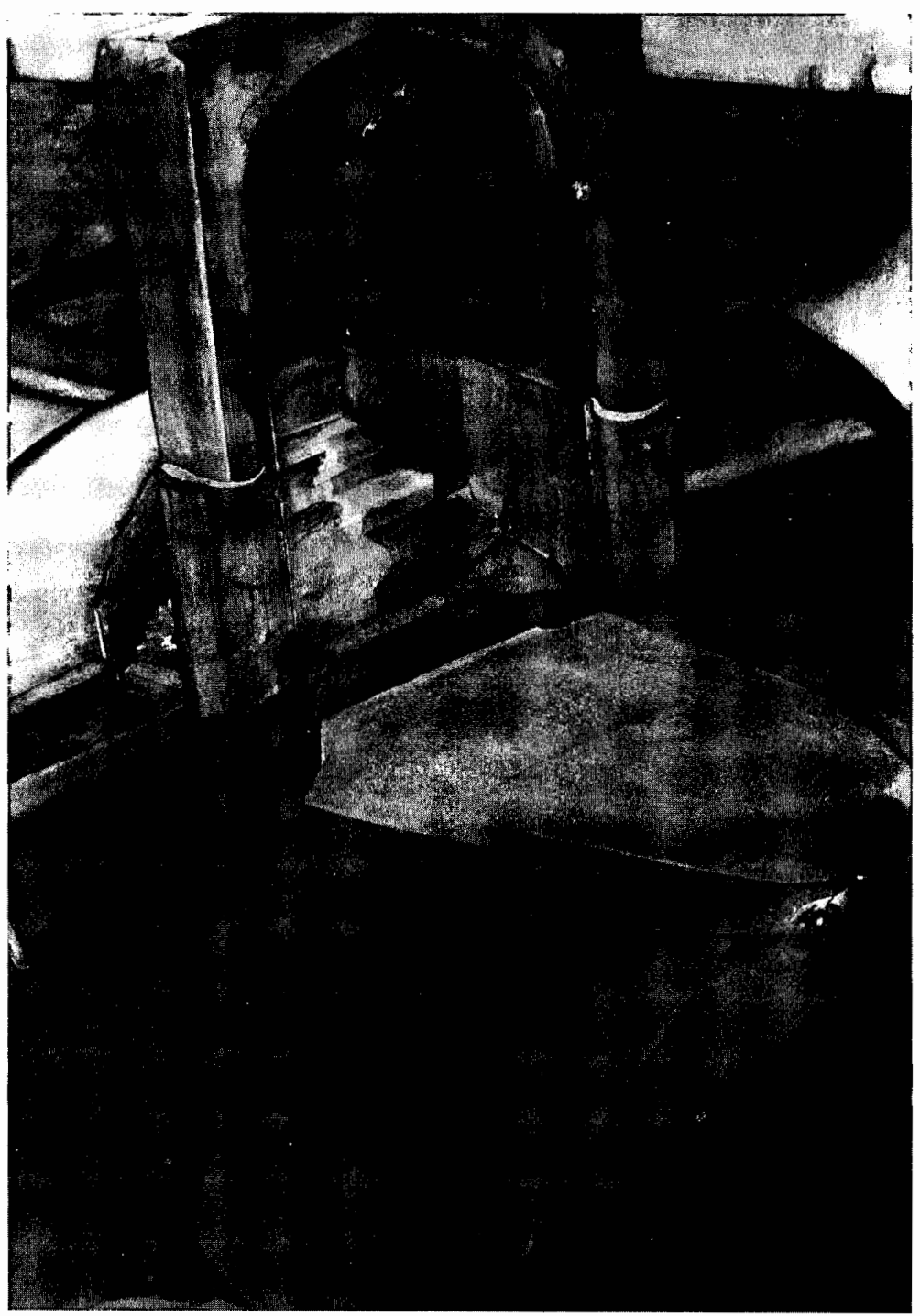

